\title{
The Cerebellar Dysplasia of Chiari II Malformation as Revealed by Eye Movements
}

\author{
Michael S. Salman, Maureen Dennis, James A. Sharpe
}

\begin{abstract}
Introduction: Chiari type II malformation (CII) is a developmental deformity of the hindbrain. We have previously reported that many patients with CII have impaired smooth pursuit, while few make inaccurate saccades or have an abnormal vestibuloocular reflex. In contrast, saccadic adaptation and visual fixation are normal. In this report, we correlate results from several eye movement studies with neuroimaging in CII. We present a model for structural changes within the cerebellum in CII. Methods: Saccades, smooth pursuit, the vestibulo-ocular reflex, and visual fixation were recorded in 21 patients with CII, aged 8-19 years and 39 age-matched controls, using an infrared eye tracker. Qualitative and quantitative MRI data were correlated with eye movements in 19 CII patients and 28 controls. Results: Nine patients with CII had abnormal eye movements. Smooth pursuit gain was subnormal in eight, saccadic accuracy abnormal in four, and vestibulo-ocular reflex gain abnormal in three. None had fixation instability. Patients with CII had a significantly smaller cerebellar volume than controls, and those with normal eye motion had an expanded midsagittal vermis compared to controls. However, patients with abnormal eye movements had a smaller (non-expanded) midsagittal vermis area, posterior fossa area and medial cerebellar volumes than CII patients with normal eye movements. Conclusions: The deformity of CII affects the structure and function of the cerebellum selectively and differently in those with abnormal eye movements. We propose that the vermis can expand when compressed within a small posterior fossa in some CII patients, thus sparing its ocular motor functions.
\end{abstract}

RÉSUMÉ: Mouvements oculaires révélant une dysplasie cérébelleuse dans la malformation de Chiari de type II. Contexte : La malformation de Chiari de type II (CII) est un défaut du développement du cerveau postérieur. Nous avons déjà rapporté que les patients porteurs de CII ont une atteinte de la poursuite oculaire lente et qu'un petit nombre ont des saccades imprécises ou un réflexe vestibulo-oculaire anormal. Par contre, l'adaptation saccadique et la fixation visuelle sont normales. Dans cet article, nous établissons la corrélation entre les résultats des études de mouvements oculaires et la neuroimagerie dans le CII. Nous présentons également un modèle de changements structurels dans le cervelet des patients atteints de CII. Méthodes : Nous avons enregistré, au moyen d'un traceur oculaire à infrarouge, les saccades, la poursuite oculaire lente, le réflexe vestibulo-oculaire et la fixation visuelle chez 21 patients atteints de CII âgés de 8 à 19 ans et chez 39 témoins appariés pour l'âge. Les données qualitatives et quantitatives de l'IRM ont été corrélées aux mouvements oculaires des 19 patients et des 28 témoins. Résultats: Neuf patients atteints de CII avaient des mouvements oculaires anormaux. Le gain de poursuite lente était sous la normale chez 8, la précision saccadique était anormale chez 4 et le gain du réflexe vestibulo-oculaire était anormal chez 3. Aucun avait une fixation instable. Les patients atteints de CII avaient un volume cérébelleux significativement plus petit que les témoins et ceux qui avaient des mouvements oculaires normaux avaient un vermis mésosagittal plus large par rapport aux témoins. Cependant, les patients qui avaient des mouvements oculaires anormaux avaient un vermis mésosagittal plus étroit (non agrandi), une région de la fosse postérieure et un volume cérébelleux médian plus petits que les patients atteints de CII qui avaient des mouvements oculaires normaux. Conclusions : La malformation de CII affecte la structure et la fonction du cervelet de façon sélective et différente chez ceux qui ont des mouvements oculaires anormaux. Nous proposons que le vermis puisse s'élargir quand il est comprimé dans une petite fosse postérieure chez certains patients atteints de CII, épargnant ainsi les fonctions motrices oculaires.

Can. J. Neurol. Sci. 2009; 36: 713-724

Chiari type II malformation (CII) is one of the most prevalent congenital deformities of the hindbrain (brainstem and cerebellum). There is early mechanical compression on the developing hindbrain in CII, as well as additional effects caused by the accompanying hydrocephalus. ${ }^{1}$ One prevailing theory is that the deformity of CII occurs secondary to mechanical compression of hindbrain structures caused by a small posterior fossa. ${ }^{2}$ The small size of the posterior fossa in CII is proposed to be caused by cerebrospinal fluid (CSF) leak through the spinal defect in spina bifida meningomyelocele, which always accompanies CII. ${ }^{2}$ This leak prevents distension of the embryonic ventricular system through the pressure that would be generated from normal CSF production and prevents expansion of the posterior fossa. ${ }^{2}$ Another proposal is that $\mathrm{CII}$ is caused by

From the Section of Pediatric Neurology (MSS), Children's Hospital, University of Manitoba, Winnipeg, Manitoba; Program in Neurosciences and Mental Health (MD), The Hospital for Sick Children; Division of Neurology (JAS), University Health Network; University of Toronto (MD, JAS), Toronto, Ontario, Canada. Received April 6, 2009. Final Revisions Submitted June 26, 2009. Correspondence to: Michael S. Salman, Section of Pediatric Neurology, Children's Hospital, AE 308, 820 Sherbrook Street, Winnipeg, Manitoba, R3A 1R9, Canada. 
primary hindbrain dysgenesis. ${ }^{3}$ These theories are not mutually exclusive.

Chiari type II malformation is commonly present in patients with spina bifida meningomyelocele. Hydrocephalus requires shunting in the majority of patients with CII. ${ }^{4-6}$ The posterior fossa contents are crowded in CII. The superior part of the cerebellar vermis is shifted upwards and the inferior vermis herniates below the foramen magnum. Agenesis or hypoplasia of the lateral cerebellar hemispheres has been reported. ${ }^{7}$ The cerebellum wraps around the brainstem. ${ }^{7}$ The brainstem is stretched inferiorly, often lying at the foramen magnum or in the cervical spinal canal. ${ }^{7}$ The mesencephalic tectum appears like a beak. ${ }^{7}$ Reduced cerebellar volume, weight, and cell content in CII have been reported in several studies.$^{8-16}$ The small cerebellar size has been attributed to crowding and mechanical compression, which has been presumed to lead to secondary ischemic changes and parenchymal loss. ${ }^{11,12}$

In addition to the detrimental effects of hydrocephalus on the developing brain in CII, there is evidence for cerebellar dysfunction being the cause of some fundamental deficits in patients with CII. The cerebellum participates in the timing of motor and cognitive processes. ${ }^{17-20}$ Perception and motor timing deficits are reported in patients with spina bifida meningomyelocele and CII. ${ }^{16}$ Further, cerebellar skeletal motor and speech deficits are features of CII. ${ }^{21,22}$ Case reports of eye movement abnormalities in CII, such as various types of nystagmus and saccadic dysmetria, also implicate cerebellar dysfunction. ${ }^{23-26}$

\section{Using eye movements to investigate the effects of Chiari type II malformation on hindbrain function}

It is not known if neural circuits in the hindbrain regions affected by the deformity of CII undergo adaptation and plastic changes sufficient to preserve their function. This is an important issue for any future development of targeted rehabilitation strategies.

The specific issue we investigated involves motor function. Although information is available on the adverse effects of this deformity on cognitive function, ${ }^{21,27,28}$ less is known about its effects on motor function. The cerebellar vermis is involved in processing and coordinating gait; however, this is difficult to investigate in patients with CII because they have a spinal cord defect (meningomyelocele) that causes upper and lower motor neuron dysfunction, which impairs their ambulation. ${ }^{22,29}$ Therefore, the effects of the deformity of CII on gait cannot be investigated easily, accurately or independently of the accompanying spinal cord lesion.

Our investigation has focused on eye movements, which provide a distinctive perspective on motor function and its neural basis. Eye movements are unaffected by diseases that affect the spine and can be quantified more readily and precisely than skeletal motor function. Limb motion is complicated by multiple joints, proprioceptive afferent inputs, stretch reflexes, and variable mechanical loads, ${ }^{26,30}$ whereas ocular motion is governed by the mechanics of the orbital plant, and visual feedback, with little or no proprioceptive information.

The cerebellum plays a crucial part in guiding eye movements and is also involved in ocular motor learning. It participates in visual fixation, binocular alignment, saccade accuracy, smooth ocular pursuit generation, vestibulo-ocular reflex (VOR) regulation, and adaptations of saccades, smooth pursuit and the VOR to altered visual information and to disease. ${ }^{26}$ Vermis lobules VI and VII, also called the ocular motor vermis, and the fastigial nucleus determine saccade accuracy, ${ }^{31}$ the flocculus and paraflocculus regulate image stabilization on the retina, ${ }^{32}$ while the nodulus and ventral uvula (vermis lobules IX and X) are important for vestibular velocity storage mechanisms, ${ }^{26}$ and transforming head-centered vestibular afferent signals into earthreferenced self-motion and spatial orientation signals. ${ }^{33}$ Therefore, different classes of eye movements can be used to study cerebellar function.

The effects of CII deformity on the neuronal circuits involved in eye movement processing had not been studied systematically. Although several case reports are available on the ocular motor abnormalities seen in patients with Chiari malformations, ${ }^{23-25,34-}$ 41 such reports lack normal control subjects and some are confounded by the presence of acute hydrocephalus..$^{26,37}$ In addition, all of these reports are biased by selection of subjects with the most prominent clinical signs.

Distinction between type I and type II Chiari malformations is important because the two disorders have different presentations, associations, etiologies, and MRI findings. ${ }^{7}$ In one uncontrolled study of 28 adults and children with spina bifida meningomyelocele and $\mathrm{CII},{ }^{23}$ eye movements were recorded on a videotape and analyzed qualitatively afterwards. The authors reported horizontal nystagmus in 17 participants and vertical nystagmus in three participants. None had downbeat nystagmus. Horizontal saccades were abnormal in three. Ten participants had saccadic horizontal smooth pursuit and three had vertical saccadic smooth pursuit.

Other uncontrolled studies have been conducted mainly in adults with Chiari type I,,$^{34,35,38-39}$ or type II, ${ }^{35-37}$ malformations. These studies reported convergence nystagmus, ${ }^{34}$ impaired smooth pursuit, ${ }^{34,35,37,38}$ hypometric saccades,${ }^{34,35}$ hypermetric saccades ${ }^{38}$ internuclear ophthalmoplegia, ${ }^{36,37}$ and impaired VOR. ${ }^{37}$ Those authors used electro-oculography (EOG), known to have both unstable baseline and low resolution because of low signal to noise ratio, to record eye movements. Others used the scleral search coil techniques, ${ }^{40,41}$ considered to be the gold standard for recording eye movement, ${ }^{26}$ to describe two adults with Chiari I malformation, ${ }^{40}$ who had disjunctive vertical jerk nystagmus with one eye beating upwards while the other eye was beating downwards, and five adults with Chiari I malformation, ${ }^{41}$ who presented with acquired esotropia, attributed to divergence palsy.

We have reported ocular motor function in patients with CII. ${ }^{42-46}$ Many typically make accurate saccades, ${ }^{42}$ and are capable of motor learning as demonstrated by adapting their saccade amplitudes to backward target displacement during saccades. ${ }^{43}$ These findings suggest that the ocular motor functions of cerebellar vermis lobules VI and VII and the fastigial nuclei are generally intact despite the deformity of $\mathrm{CII},{ }^{42,43}$ because these regions play an important role in processing saccadic amplitude accuracy and saccadic adaptation. ${ }^{31,47}$ In contrast, smooth ocular pursuit is impaired in patients with CII and nystagmus but not in patients with CII who do not have nystagmus. ${ }^{44}$ This implicates functional impairment of cerebellar flocculus and paraflocculus or their brainstem connections in some patients with $\mathrm{CII} .{ }^{44}$ 
Furthermore, many patients with CII typically have a normal angular VOR performance in response to active head motion. ${ }^{45}$ However, CII is associated with impaired VOR performance in few patients. ${ }^{45}$ Low VOR gain is attributed to brainstem damage and high VOR gain to cerebellar dysfunction. Fixation stability in patients with CII is similar to that in healthy controls. ${ }^{46}$

In this case-controlled analysis, we report the clinical features of a cohort of patients with CII and correlate their ocular motor findings with qualitative and quantitative neuroimaging abnormalities on MRI. Our objective was to describe the extent to which this chronic developmental deformity impairs the function of different classes of eye movements and relate them to neuroimaging abnormalities. Finally, we present a model for structural changes within the cerebellum in CII based on ocular motor functions.

\section{Methods}

\section{Participants}

Twenty-three patients with CII were chosen randomly from a group of participants in a spina bifida project funded by the US National Institute of Child Health and Human Development. Inclusion criteria were an age range between 8 and 19 years, shunted hydrocephalus, a verbal or performance IQ of 70 or above, and best corrected monocular visual acuity of at least 20/30.

Recording eye movements can be difficult and challenging in children, especially in those with disability. Restricting the current study to participants with a verbal or performance IQ greater than 70 was necessary, where patients' comprehension and cooperation are paramount, and selected better functioning individuals with CII.

Exclusion criteria were visual field defect on clinical examination, paralytic strabismus, nystagmus on clinical examination within the recorded range of eye movements because nystagmus could interfere with the eye movement analysis, ${ }^{23}$ medication with drugs that might interfere with eye movements, and ocular, psychiatric or neurological disorders unrelated to CII.
One patient declined to participate and another patient was not available for testing on the day of the experiment. Seven wore glasses. Four were myopic and three were hyperopic. The majority (19 of 21) had CSF shunting during the first seven weeks of life (15 of those 19 were shunted during the first two weeks of life). Demographic details of the participants are shown in Table 1. None had blurred vision, nausea, vomiting, vertigo, oscillopsia, or reading difficulties. Twenty participants used a urinary catheter. Eleven were taking oxybutynin to control bladder symptoms associated with the meningomyelocele. Four of those 11 patients also took nitrofurantoin or Septra for urinary tract infection prophylaxis. One patient was taking domperidone and omeprazole. None of these drugs affect eye movements. One participant was color-blind. Seven had esotropia and two had exotropia, ranging between 6-35 prism diopters. One had hypertropia (4 prism diopters). All had normal pupillary reaction to light, funduscopy, and other cranial nerve functions. Other clinical features are displayed in Table 2.

The control group was 40 normal children and adolescents between 8 and 19 years of age recruited by local advertising. Fourteen were myopic and wore glasses. One was hyperopic and rarely wore glasses. One volunteer later declined participation. Each subject underwent a clinical assessment including history followed by general, neurological, and neuro-ophthalmological examinations to ensure their eligibility. One participant with CII and another in the control group did not complete some of the tasks.

The study was in accord with the declaration of Helsinki guidelines. Ethical approval was obtained from the Research Ethics Boards at the Hospital for Sick Children and the University Health Network, Toronto. Written consent was obtained from all participants or their legal guardian.

Power calculations. We calculated power by using means and standard deviations of a visually guided upper limb task for spina bifida meningomyelocele and control groups. ${ }^{48,49}$ A sample size of 26 per group would detect significant difference between the CII and control groups with $80 \%$ power, and $5 \%$ level of confidence based on a two-sample t-test power analysis. ${ }^{49} \mathrm{~A}$

Table 1: Demographic information of the control and Chiari type II malformation (CII) groups

\begin{tabular}{lll}
\hline & Control group & CII group \\
\hline Number of participants & 39 & 21 \\
Gender & 21 males & 11 males \\
Age (SD) in years & $13.7(3.5)$ & $14.3(3.2)$ \\
Spinal lesion level: & Not applicable & \\
$\quad$ & & $6(4$ at T12, 1 at T10, 1 at T8) \\
$\quad$ Lower (T12 and above) & & $15(3$ at L1, 2 at L2, 1 at L3, 4 at L4, 5 at L5) \\
Age at spinal defect closure (days) & Not applicable & 13 on day 1,7 on day 2, 1 on day 21 \\
Shunted hydrocephalus & Not applicable & 21 \\
$\quad$ No shunt revision & & 5 \\
$\quad$ One shunt revision & & 9 \\
$\quad$ Two shunt revisions & & 4 \\
$\quad$ Four shunt revisions & & 2 \\
Ten shunt revisions & & 1 \\
\hline
\end{tabular}


Table 2: Clinical findings in the control and Chiari type II malformation (CII) groups

\begin{tabular}{|c|c|c|}
\hline \multicolumn{2}{|c|}{ Control group (\%) } & \multirow{2}{*}{$\begin{array}{c}\text { CII group (\%) } \\
8(38)\end{array}$} \\
\hline Occasional headache & $7(18)$ & \\
\hline Seizures in the past & $2(5)$ & $3(14.3)$ \\
\hline Dizziness & 0 & $1(4.8)$ \\
\hline Tinnitus & 0 & $2(9.5)$ \\
\hline Strabismus & $3(7.7)$ & $10(47.6)$ \\
\hline Strabismus surgery & $1(2.6)$ & $2(9.5)$ \\
\hline Mean head circumference $\{\mathrm{cm}\}$ & $55.3[\mathrm{~N}=38]$ & $55.6[\mathrm{~N}=20]$ \\
\hline Abnormal stereo test - concentric circles & 1 of $38(2.6)$ & 5 of $20(25)$ \\
\hline $\begin{array}{l}\text { Median reduction in number of visual acuity lines [range] } \\
\text { on dynamic visual acuity test }\end{array}$ & $3[2-6]$ & $4.3[0-9]$ \\
\hline Horizontal saccadic smooth pursuit & $1(2.6)$ & $9(43)$ \\
\hline Vertical saccadic smooth pursuit & 0 & $7(33.3)^{*}$ \\
\hline Hypometric horizontal saccades & 0 & $1(4.8)^{*}$ \\
\hline Hypermetric horizontal saccades & 0 & $1(4.8)^{*}$ \\
\hline Hypo- or hypermetric vertical saccades & 0 & 0 \\
\hline Impaired horizontal optokinetic response & 0 of 37 & 4 of $18(22.2)$ \\
\hline Impaired vertical optokinetic response & 0 of 37 & 11 of $18(61)$ \\
\hline Abnormal visually-enhanced horizontal VOR & 0 & $1(4.8)$ \\
\hline Abnormal visually-enhanced vertical VOR & 0 & 0 \\
\hline Abnormal horizontal VOR cancellation & 3 of $38(8)$ & 16 of $20(80)$ \\
\hline $\begin{array}{l}\text { Abnormal horizontal head impulse test } \\
\text { Nystagmus }^{\dagger}\end{array}$ & 3 of $33(9)$ & 9 of $18(50)$ \\
\hline Hypotonia of the upper limbs & 0 & $1(4.8)$ \\
\hline Hypertonia of the upper limbs & 0 & $1(4.8)$ \\
\hline Weakness of the upper limbs & 0 & $1(4.8) \mathrm{MRC} 4$ \\
\hline Intention tremor & 0 & $1(4.8)$ \\
\hline Dysmetria & 0 & $3(14.3)$ \\
\hline Dysdiadochokinesia & 0 & $2(9.5)$ \\
\hline Hypotonia of the lower limbs & 0 & $20(95.2)$ \\
\hline Weakness of the lower limb & 0 & 21 (100) MRC 1-4 \\
\hline Brisk upper limb reflexes & 0 & $1(4.8)$ \\
\hline Absent or reduced knee jerk & 0 & $6(28.6)$ \\
\hline Absent or reduced ankle jerk & 0 & $21(100)$ \\
\hline Babinski sign & 0 & $1(4.8)$ \\
\hline Abnormal upper limb sensory exam & 0 & 0 \\
\hline Abnormal lower limb sensory exam ${ }^{\dagger \dagger}$ & 0 & $21(100)$ \\
\hline Ambulatory & $39(100)$ & $9(43)$ \\
\hline Normal gait & $39(100)$ & 0 \\
\hline
\end{tabular}

$\dagger$ Nystagmus was present on clinical examination but not in the range of the eye movement tasks. In seven of the eight participants, a sub-clinical small amplitude nystagmus was also noted on eye movement recordings. * Not confirmed by oculographic recording. MRC is Medical Research Council Grade, $\dagger \dagger$ Sensation to pin prick, joint position sense, and vibration sense.

larger sample size and unequal numbers of participants in each group changed the power to $82 \% .^{49}$

Hydrocephalus. We distinguished three shunt groups. Group 1 had no shunt revisions, Group 2 had one shunt revision, and Group 3 had $\geq$ two shunt revisions.

Nystagmus. We excluded patients with nystagmus if the nystagmus was detectable within the range of the eye movement tasks $\left( \pm 20^{\circ}\right)$ on clinical examination. We included eight patients with nystagmus, which was clinically apparent only in eccentric gaze. In seven of these patients, there was a predominantly horizontal, low amplitude $\left(<2^{\circ}\right)$, gaze-evoked nystagmus within $\pm 20^{\circ}$ of forward gaze evident only on eye movement recording.
Eye movements. Three classes of eye movements and fixation were recorded from the viewing eye while covering the other eye using paradigms reported in detail elsewhere. ${ }^{42,44-46}$ These were visually-guided saccades, smooth ocular pursuit, and the VOR during active head motion. We also recorded fixation stability. In addition, saccadic adaptation was investigated to test ocular motor learning. ${ }^{43}$

MRI qualitative data. Nineteen of the 21 participants with CII had brain MRI without artifact. Eighteen scans were suitable for analysis for this part of the investigation. The following details, whether present or absent, were gathered from each MRI by a neuroradiologist based on a standardized data collection 


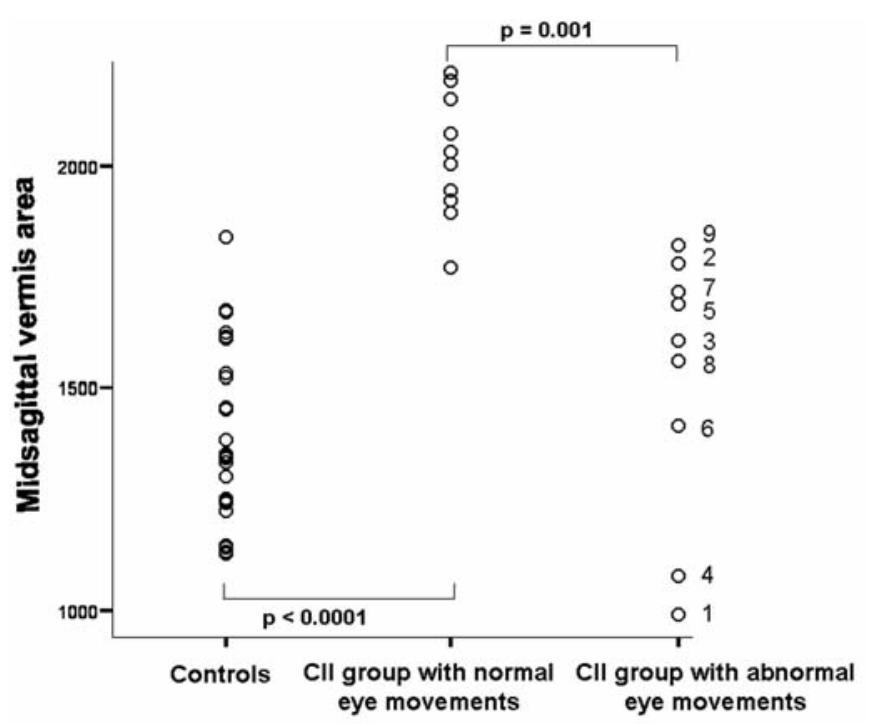

Figure 1: Midsagittal vermis areas $\left(\mathrm{mm}^{2}\right)$ are shown in the controls, patients with CII who had normal eye movements, and patients with CII who had abnormal eye movements. The vermis is significantly expanded in patients with CII who had normal eye movements (the numbers 1-9 on the right correspond to the participants' number as presented in Table 3).

sheet: crowding of the cerebral cortex gyri, abnormal corpus callosum, abnormal midbrain, pons, or medulla, tectal beaking, small posterior fossa size; abnormal cerebellum, small cerebellum, dysplastic cerebellum, upward herniation of the cerebellum, abnormal vermis or cerebellar hemisphere, syrinx, periventricular leukomalacia, heterotopia, and aqueduct stenosis. The lowest level of downward herniation was also recorded.

Linear and area measurements on MRI. In addition to the 19 participants with CII who had MRI, six of the 39 controls who had eye movements recordings, and a further 22 healthy controls, who did not have eye movement recordings, also had brain MRI for comparison. Therefore, neuroimaging was available on 28 control participants. We used a software program (Ataman software Inc., 1998) to measure distances and calculate areas of selected regions on a $\mathrm{T} 1$ or $\mathrm{T} 2$ weighted midsagittal MRI image. The following were measured: The longest transverse and longitudinal distances across the vermis, herniation distance and area below foramen magnum, intracranial fossa, posterior fossa, cerebellar vermis, vermis lobules I-V, and vermis lobules VI-VII areas, as described previously. ${ }^{50}$ All of these measurements were found to be significantly different in a larger cohort of children and adolescents with $\mathrm{CII}$ in comparison to healthy children and adolescents. $^{50}$

Volume measurements on MRI. Of all participants who had brain MRI, cerebellar volume measurements were available in eight participants with CII, two healthy controls who had eye movement recordings, and another eight healthy controls who did not have eye movement recordings. Therefore, the number of the normal control participants who had cerebellar volumes measured on MRI scan was 10. The rest of our participants either

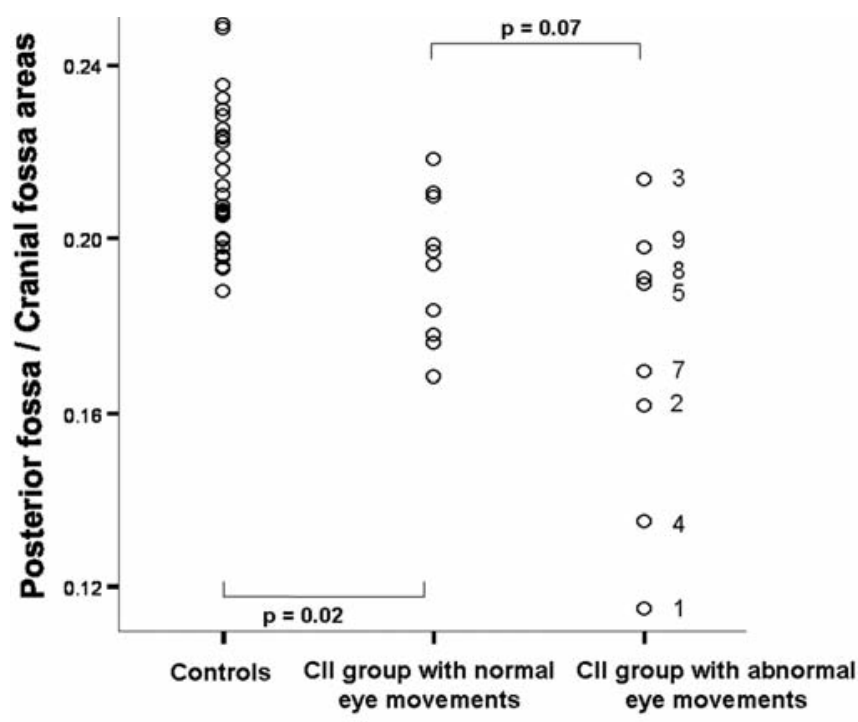

Figure 2: The ratios of midsagittal posterior fossa to cranial fossa areas are shown in the controls, patients with CII who had normal eye movements, and patients with CII who had abnormal eye movements. This ratio, which takes into account variations in posterior fossa size by age and gender, is significantly smaller in patients with CII. In addition, there is a trend for this ratio to be smaller in patients with CII who had abnormal eye movements (the numbers on the right correspond to the participants' number as presented in Table 3).

had artifacts or inadequate quality scans that precluded volumetric analysis.

Details of acquisition, processing, and automatic segmentation of the images are described in detail in the same participants in another report. ${ }^{16}$ Cerebellar volume measures were computed automatically following mask generation. ${ }^{16} \mathrm{CSF}$, white and grey matter volumes were also measured. ${ }^{16}$ Medial and lateral cerebellar volumes were calculated based on the assumption that all structures within the cerebellum undergo atrophy in a proportional manner in CII as was thought at the time of the MRI imaging analyses. Thus, the medial and lateral cerebellar volumes represent only an approximation for vermis and cerebellar hemisphere volumes.

\section{Analyses}

A Statistical Package for Social Sciences, version 15.0 (SPSS Inc., Chicago, Il, USA) was used to analyze the data. We checked the normality of data distribution using the mean, median, standard deviation, skewness, kurtosis, and box plots. ${ }^{49}$

We correlated results from all eye movement studies in these patients, which have been reported, ${ }^{42-46}$ with the neuroimaging data.

Qualitative neuroimaging data were analyzed using chisquared test. Quantitative group differences were analyzed using the Student t-tests for normally distributed data or MannWhitney $U$ tests for non-parametric data. ${ }^{49}$ Pearson and Spearman correlation tests were used to investigate structural- 
functional correlations. Multiple group comparisons were investigated using one-way analysis of variance (ANOVA) for normally distributed data or Kruskal-Wallis test for nonparametric data. ${ }^{49}$ Significance was defined by $\mathrm{p}$ values $<0.05$.

\section{RESULTS}

Nine of the 21 participants with CII had abnormal eye movement recordings. The VOR alone was impaired in one patient; smooth pursuit impairment alone was recorded in four; smooth pursuit and saccadic amplitude accuracy were impaired in two; and smooth pursuit, saccadic amplitude accuracy, and VOR were all impaired in two patients (Table 3). Smooth pursuit was impaired in patients with CII who had nystagmus. We classified the patients with abnormal eye movements further into subgroups based on the type(s) of eye movement abnormality and the most likely anatomical locations for these eye movement abnormalities (Table 4).

Saccadic adaptation, age, gender, the percentage of participants with upper spinal lesion level, and the number of shunt revisions were similar in participants with CII who had normal eye movements $(\mathrm{N}=12)$ in comparison to participants with CII who had abnormal eye movements $(\mathrm{N}=9), \mathrm{p} \geq 0.13$.

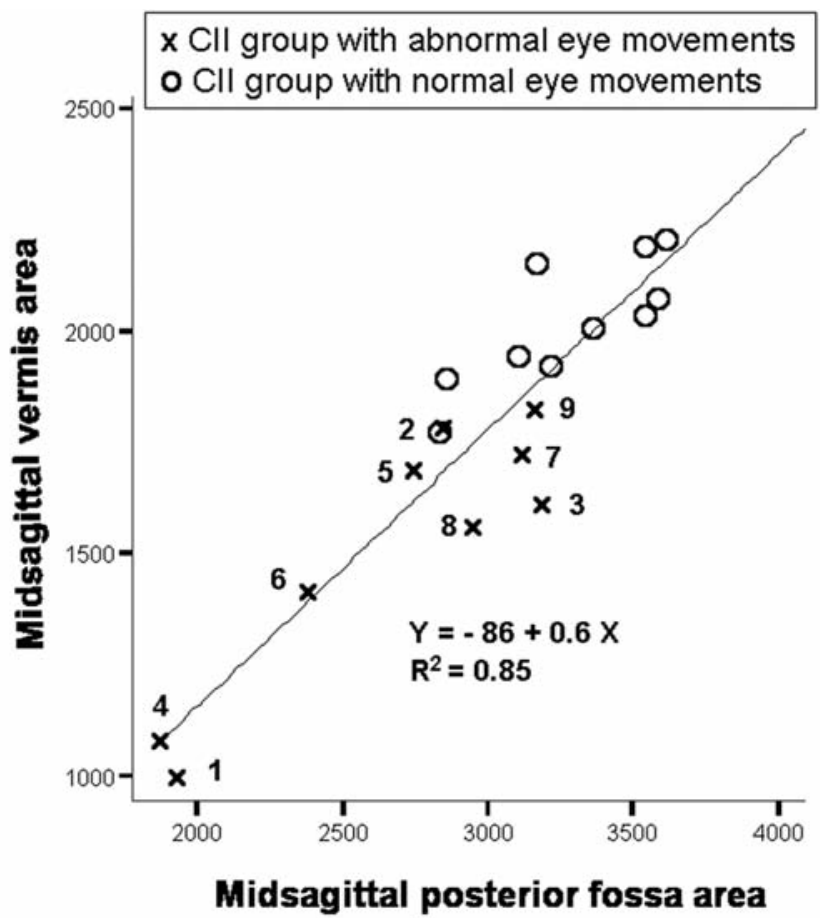

Figure 3: This graph illustrates a significant correlation between the midsagittal vermis and posterior fossa areas $\left(\mathrm{mm}^{2}\right)$ in patients with CII. Patients with CII who had abnormal eye movements (marked as ' $x$ ' with the participants number, as presented in Table 3) all had a markedly smaller (non-expanded) vermis area and a relatively smaller posterior fossa area in comparison to patients with CII who had normal eye movements. In addition, patients with impaired smooth pursuit and saccade accuracy (participants Number 1, 4, 6) had the smallest midsagittal vermis and posterior fossa areas.
None of the qualitative neuroimaging data (available in 18 patients with CII) were significantly different between patients in the CII group who had normal eye movements $(\mathrm{N}=10)$ in comparison to patients in the CII group who had abnormal eye movements $(\mathrm{N}=8), \mathrm{p} \geq 0.11$.

Midsagittal MRI measurements (available in 19 patients) were then compared between patients who had abnormal eye movements $(\mathrm{N}=9)$ and patients who had normal eye movements $(\mathrm{N}=10)$. The midsagittal vermis area was expanded significantly in patients who had normal eye movements (Figure 1 ), while the midsagittal vermis area in the patients who had abnormal eye movements and controls were similar $(p=0.15)$. The results were unchanged and remained highly significant $(\mathrm{p}=$ 0.001 ) after taking the effects of age, gender, and cranial fossa area variations into consideration among all participants.

Midsagittal vermis lobules I-V area was expanded significantly in patients who had normal eye movements $(\mathrm{N}=$ $10)$ in comparison with patients who had abnormal eye movements $(\mathrm{N}=7, \mathrm{p}=0.04)$ and controls $(\mathrm{N}=28, \mathrm{p}<0.0001)$. There was a trend for the midsagittal vermis lobules I-V area to be expanded in the CII patient group with abnormal eye movements $(\mathrm{N}=7)$ in comparison with the control group $(\mathrm{N}=$ $28, \mathrm{p}=0.072)$.

Midsagittal vermis lobules VI-VII area was also expanded significantly in patients who had normal eye movements $(\mathrm{N}=$ 10) in comparison with patients who had abnormal eye movements $(\mathrm{p}=0.01)$ and controls $(\mathrm{N}=28, \mathrm{p}<0.0001)$. In addition, midsagittal vermis lobules VI-VII area was expanded significantly in the $\mathrm{CII}$ group with abnormal eye movements $(\mathrm{N}$ $=7)$ in comparison with the control group $(\mathrm{N}=28, \mathrm{p}=0.007)$. Patients who had abnormal eye movements had smaller midsagittal posterior fossa area than patients with CII who had

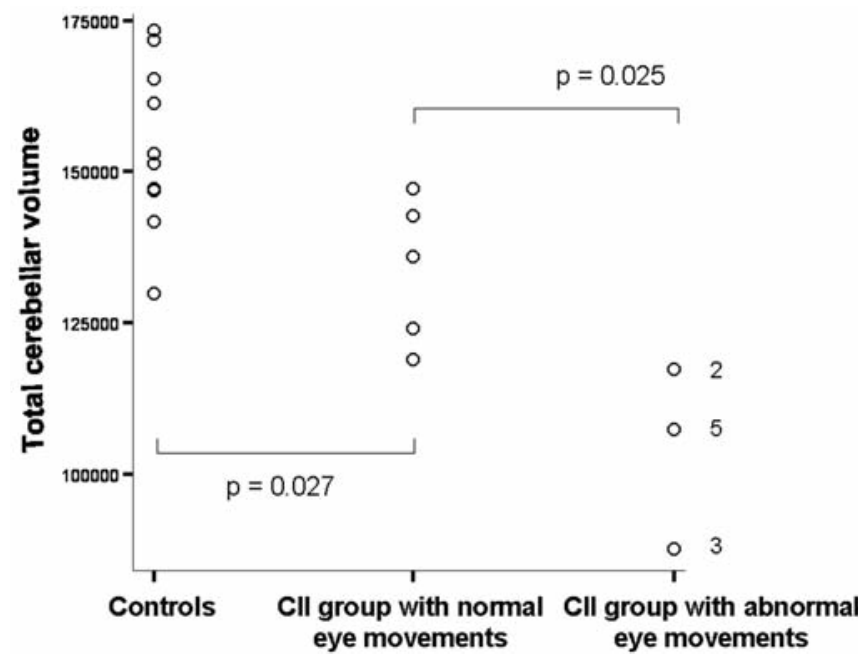

Figure 4: Total cerebellar volumes $\left(\mathrm{mm}^{3}\right)$ are shown in the controls, patients with CII who had normal eye movements, and patients with CII who had abnormal eye movements. The total cerebellar volume is smallest in patients with CII who had abnormal eye movements (the numbers on the right correspond to the participants' number as presented in Table 3). 
Table 3: Summary of the participants with Chiari II who had eye movement abnormalities

\begin{tabular}{|c|c|c|c|c|c|c|c|c|c|}
\hline Participant number & 1 & 2 & 3 & 4 & 5 & 6 & 7 & 8 & 9 \\
\hline Age (y)/gender & $18 / \mathrm{M}$ & $15 / \mathrm{M}$ & $13 / \mathrm{F}$ & $17 / \mathrm{F}$ & $13.5 / \mathrm{F}$ & $18 / \mathrm{M}$ & $9 / \mathrm{M}$ & $11.5 / \mathrm{F}$ & $17 / \mathrm{M}$ \\
\hline Spinal level & Lum 4 & Lum 5 & Lum 1 & $\mathrm{~T} 10$ & Lum 1 & Lum 5 & $\mathrm{~T} 12$ & Lum 5 & Lum 3 \\
\hline Nystagmus & + & + & + & + & - & + & + & + & + \\
\hline Shunt revisions & 1 & 10 & 1 & 0 & 1 & 2 & 4 & 1 & 2 \\
\hline Saccade adaptation & - & + & - & + & + & - & - & + & - \\
\hline H saccades & $\mathrm{N}$ & $\mathrm{N}$ & $\mathrm{N}$ & Hyper & $\mathrm{N}$ & Нуро & $\mathrm{N}$ & $\mathrm{N}$ & Нyро \\
\hline V saccades & Hyper $^{*}$ & $\mathrm{~N}$ & $\mathrm{~N}$ & Нypo & $\mathrm{N}$ & Нypo & $\mathrm{N}$ & $\mathrm{N}$ & Нypo \\
\hline $\mathrm{H} \mathrm{SP}$ at $0.25 \mathrm{~Hz}$ & $\mathrm{~L}$ & $\mathrm{~N}$ & $\mathrm{~N}$ & $\mathrm{~L}$ & $\mathrm{~N}$ & $\mathrm{~N}$ & $\mathrm{~L}$ & Sl. L & $\mathrm{L}$ \\
\hline $\mathrm{H} \mathrm{SP}$ at $0.5 \mathrm{~Hz}$ & $\mathrm{~L}$ & S1. L & S1. L & $\mathrm{L}$ & $\mathrm{N}$ & $\mathrm{L}$ & $\mathrm{L}$ & $\mathrm{L}$ & Sl. L \\
\hline V SP at $0.25 \mathrm{~Hz}$ & $\mathrm{~N}$ & $\mathrm{~N}$ & $\mathrm{~N}$ & $\mathrm{~N}$ & $\mathrm{~N}$ & $\mathrm{~N}$ & $\mathrm{~N}$ & $\mathrm{~N}$ & $\mathrm{~N}$ \\
\hline V SP at $0.5 \mathrm{~Hz}$ & $\mathrm{~N}$ & $\mathrm{~N}$ & $\mathrm{~N}$ & $\mathrm{~N}$ & $\mathrm{~N}$ & $\mathrm{~N}$ & $\mathrm{~N}$ & $\mathrm{~N}$ & $\mathrm{~N}$ \\
\hline H VOR at $0.5 \mathrm{~Hz}$ & $\mathrm{~N}$ & $\mathrm{~N}$ & $\mathrm{~N}$ & I & $\mathrm{L}$ & $\mathrm{N}$ & $\mathrm{N}$ & $\mathrm{N}$ & $\mathrm{L}$ \\
\hline H VOR at $2 \mathrm{~Hz}$ & $\mathrm{~N}$ & $\mathrm{~N}$ & $\mathrm{~N}$ & I & $\mathrm{L}$ & $\mathrm{N}$ & $\mathrm{N}$ & $\mathrm{N}$ & $\mathrm{L}$ \\
\hline V VOR at $0.5 \mathrm{~Hz}$ & $\mathrm{~N}$ & $\mathrm{~N}$ & $\mathrm{~N}$ & $\mathrm{~L}$ & Sl. L & $\mathrm{N}$ & $\mathrm{N}$ & $\mathrm{N}$ & Sl. L \\
\hline V VOR at $2 \mathrm{~Hz}$ & $\mathrm{~N}$ & $\mathrm{~N}$ & $\mathrm{~N}$ & S1. L & $\mathrm{N}$ & $\mathrm{N}$ & $\mathrm{N}$ & $\mathrm{N}$ & $\mathrm{L}$ \\
\hline No. of $\mathrm{SWJ} / \mathrm{min}$. & 1 & 1 & 0 & 0 & 4 & 0 & 4 & 2 & 0 \\
\hline
\end{tabular}

M: male, F: female, Lum: lumbar, T: thoracic, +: present, -: absent, H: horizontal, V: vertical, N: normal, Hyper: hypermetric, Hypo: hypometric, SP: smooth pursuit, S1.: slight, L: low gain, I: increased gain, VOR: The vestibulo-ocular reflex, No.: number, SWJ: square wave jerks, y: years, min.: minutes. * One patient (participant 1) was not documented to have significantly abnormal saccades in our preliminary report. ${ }^{48} \mathrm{His}$ saccadic abnormality was limited to upward gaze.

normal eye movements $(\mathrm{p}=0.005)$. When variations in cranial fossa area were taken into consideration a similar trend was still evident on post hoc analysis (Figure 2).

There was a significant positive correlation between midsagittal vermis and posterior fossa areas in patients, which segregated them into two groups based on the presence or absence of eye movement abnormalities (Figure 3). In addition, patients with abnormal eye movements that were most likely caused by vermis dysfunction (i.e., smooth pursuit and saccades) tended to have the smallest midsagittal vermis and posterior fossa areas (Figure 3).

The longest longitudinal distance across the vermis was significantly larger in all CII patients $(\mathrm{N}=19)$, irrespective of their eye movements' status, in comparison with control group ( $\mathrm{N}=28, \mathrm{p}<0.0001$ for both the CII group with normal eye movements and the CII group with abnormal eye movements).
There was no significant difference in the longest longitudinal distance across the vermis between patients who had normal eye movements $(\mathrm{N}=10)$ and patients who had abnormal eye movements $(\mathrm{N}=9, \mathrm{p}=0.35)$.

The longest transverse distance across the vermis was significantly larger in CII patients who had normal eye movements $(\mathrm{N}=10)$ in comparison with the control group $(\mathrm{N}=$ $28, \mathrm{p}<0.0001)$ and the CII patients who had abnormal eye movements $(\mathrm{N}=9, \mathrm{p}=0.046)$. There was a trend for the longest transverse distance across the vermis to be larger in the CII group with abnormal eye movements $(\mathrm{N}=9)$ in comparison with the control group $(\mathrm{N}=28, \mathrm{p}=0.073)$.

Total cerebellar volumes, total cerebellar white matter volumes, and total cerebellar grey matter volumes were all significantly smaller in the CII group $(\mathrm{N}=8)$ in comparison to the controls $(\mathrm{N}=10, \mathrm{p} \leq 0.004$, Figure 4). In contrast, CSF

Table 4: Types of eye movement abnormalities in patients with Chiari type II malformation

\begin{tabular}{lll}
\hline $\begin{array}{l}\text { Participant } \\
\text { number }\end{array}$ & Eye movement abnormalities & $\begin{array}{l}\text { Proposed region(s) of } \\
\text { dysfunction }\end{array}$ \\
\hline 5 & Low VOR gain & BS \\
$2,3,7,8$ & Low SP gain & F/Pf \\
9 & Low SP, saccade amplitude, and VOR gains & F/Pf, BS, \pm OMV/Fn \\
6 & Low SP and saccade amplitude gains & F/Pf, BS or OMV/Fn \\
1 & Low SP gain and high saccade amplitude gain & F/Pf, OMV/Fn \\
4 & Low SP gain, low and high saccade amplitude and VOR & F/Pf, BS, OMV/Fn \\
& gains & \\
\hline
\end{tabular}

SP: smooth pursuit, VOR: vestibulo-ocular reflex, F/Pf: flocculus and paraflocculus, BS: brainstem, OMV/Fn: ocular motor vermis (lobules VI/VII) and fastigial nucleus ocular motor region. 


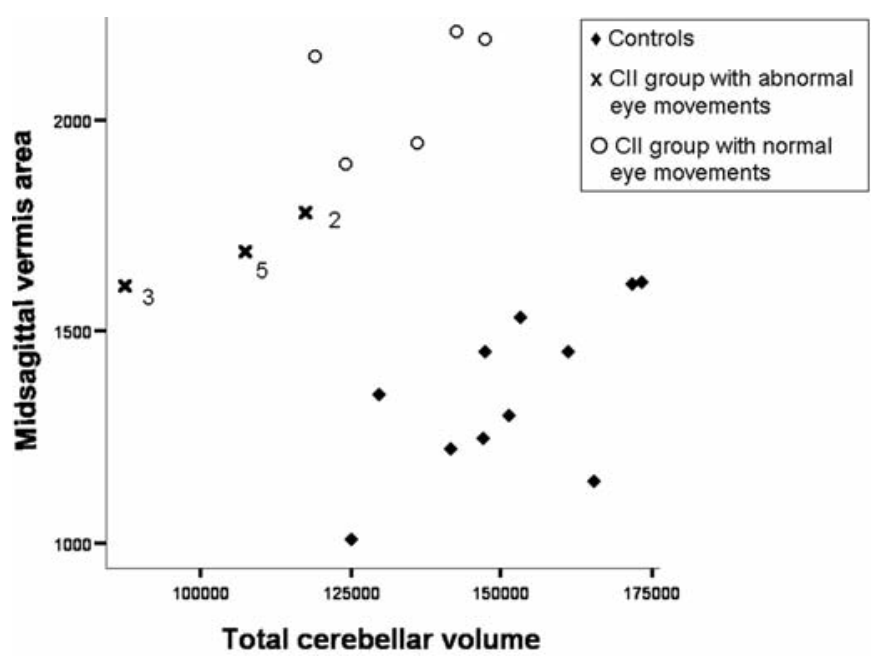

Figure 5: This graph illustrates a significant correlation between midsagittal vermis area $\left(\mathrm{mm}^{2}\right)$ and cerebellar volumes $\left(\mathrm{mm}^{3}\right)$ in patients with CII. Patients with CII who had abnormal eye movements (marked as ' $x$ ' with the participants' number, as presented in Table 3) all had a non-expanded vermis area and smaller total cerebellar volumes in comparison to patients with CII who had normal eye movements. Participants in the control group are also shown for comparison.

volumes within the fissures of the cerebellum were similar in the CII and control groups $(\mathrm{p}=0.17)$. In addition, total cerebellar volumes were significantly smaller in patients who had abnormal eye movements $(\mathrm{N}=3)$ in comparison to patients who had normal eye movements $(\mathrm{N}=5, \mathrm{p}=0.025$, Figure 4). Midsagittal vermis area was significantly smaller in CII patients who had smaller total cerebellar volume (Spearman's correlation coefficient $=0.91, \mathrm{p}=0.002, \mathrm{~N}=8$, Figure 5). These patients had abnormal eye movements. There were no significant differences in age or gender among the participants that could account for these findings.

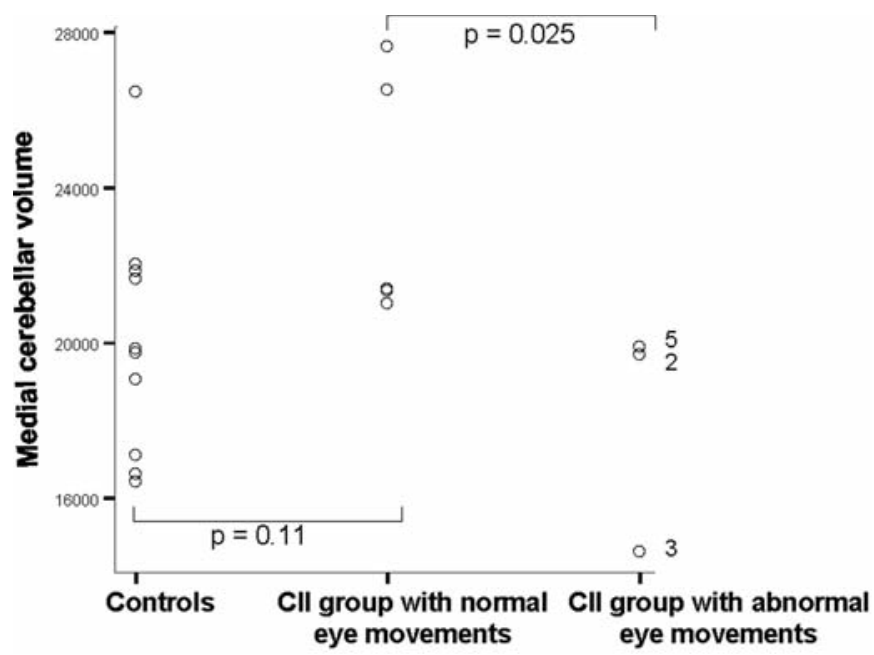

Figure 6: Medial cerebellar volumes $\left(\mathrm{mm}^{3}\right)$ are shown in the controls, patients with CII who had normal eye movements, and patients with CII who had abnormal eye movements. The medial cerebellar volumes are relatively smaller in patients with CII who had abnormal eye movements than in patients with CII who had normal eye movements (the numbers on the right correspond to the participants' number as presented in Table 3).
Medial cerebellar volumes were significantly smaller in CII participants with abnormal eye movements $(\mathrm{N}=3)$ in comparison to CII participants with normal eye movements $(\mathrm{N}=$ $5, \mathrm{p}=0.025)$, but similar to the medial cerebellar volumes in the controls $(\mathrm{N}=10, \mathrm{p}=0.4)$ (Figure 6). Lateral cerebellar volumes were significantly smaller in the entire group of CII participants $(\mathrm{N}=8)$ in comparison to the control group $(\mathrm{N}=10, \mathrm{p}<0.0001)$. In addition, lateral cerebellar volumes were significantly smaller in CII participants with abnormal eye movements $(\mathrm{N}=3)$ in comparison to $\mathrm{CII}$ participants with normal eye movements $(\mathrm{N}=$ $5, \mathrm{p}=0.025$, Figure 7).

Table 5: Summary of changes in MRI metrics of the posterior fossa and cerebellum in Chiari type II malformation (CII) in comparison to the control group (X, V, A, P, C, M, and L denote mean values of the various structures in the controls)

\begin{tabular}{|c|c|c|c|}
\hline & $\begin{array}{l}\text { Control } \\
\text { group }\end{array}$ & $\begin{array}{l}\text { CII group with normal eye } \\
\text { movements }\end{array}$ & $\begin{array}{l}\text { CII group with abnormal eye } \\
\text { movements }\end{array}$ \\
\hline Midsagittal posterior fossa area & $\mathrm{X}$ & $<\mathrm{X}$ & $<$ or $<<\mathrm{X}$ \\
\hline Midsagittal vermis area & $\mathrm{V}$ & $>\mathrm{V}$ & $\mathrm{V}$ \\
\hline $\begin{array}{l}\text { Midsagittal vermis lobules I-V } \\
\text { area }\end{array}$ & A & $>\mathrm{A}$ & A \\
\hline $\begin{array}{l}\text { Midsagittal vermis lobules VI-VII } \\
\text { area }\end{array}$ & $\mathrm{P}$ & $\gg P$ & $>\mathrm{P}$ \\
\hline Total cerebellar volume & $\mathrm{C}$ & $<\mathrm{C}$ & $<<\mathrm{C}$ \\
\hline $\begin{array}{l}\text { Medial cerebellar volume }(\approx \\
\text { vermis) }\end{array}$ & M & $\mathrm{M}^{\mathrm{a}}$ (change in shape only) & Relatively $<\mathrm{M}^{\mathrm{a}}$, similar to $\mathrm{M}$ \\
\hline $\begin{array}{l}\text { Lateral cerebellar volume }(\approx \\
\text { cerebellar hemispheres) }\end{array}$ & $\mathrm{L}$ & $<\mathrm{L}$ & $<<\mathrm{L}$ \\
\hline
\end{tabular}




\section{DISCUSSION}

Recording different classes of eye movements in CII has provided a novel perspective on motor function of the hindbrain in CII in relation to the anatomical changes in this dysplastic condition. We found that patients with CII have smaller midsagittal posterior fossa areas and cerebellar volumes. These finding are consistent with the small posterior fossa size and cerebellar atrophy reported in prior studies. ${ }^{12,13,15,51}$ The cerebellar atrophy in CII involves both the white and grey matter.

Only few MRI and autopsy studies have reported that the cerebellar loss affects the cerebellar hemispheres and usually spares the vermis. ${ }^{12,13}$ We also found that the cerebellar compression in CII does not affect all parts of the cerebellum equally. ${ }^{29,50}$ In addition, we found that the midsagittal vermis can expand rostrally, caudally, ventrally, and dorsally in some patients with CII. We propose that the midline location of the vermis allows it to expand, ${ }^{29,50}$ while the cerebellar hemispheres undergo atrophy in CII, ${ }^{11,12,14}$ presumably because they have no room to expand. ${ }^{29,50}$

Midsagittal vermis expansion, including the significant expansion of vermis lobules VI-VII area and the preserved medial cerebellar volume identified in this investigation, corresponded to sparing of ocular motor functions processed in the vermis, namely saccadic accuracy, saccadic adaptation and smooth pursuit, ${ }^{42-44}$ despite the overall size reduction in cerebellar size that accompanies the deformity of CII. This reduction in size mainly affects the cerebellar hemispheres, i.e. tissue lateral to the vermis.

However, in patients with abnormal eye movements, the midsagittal vermis area is not expanded, vermis lobules VI-VII area is only slightly expanded, and the midsagittal vermis area occupies a smaller midsagittal posterior fossa area. In addition, the medial cerebellar volume, an approximate measure of vermis size, is significantly reduced in those CII patients with abnormal

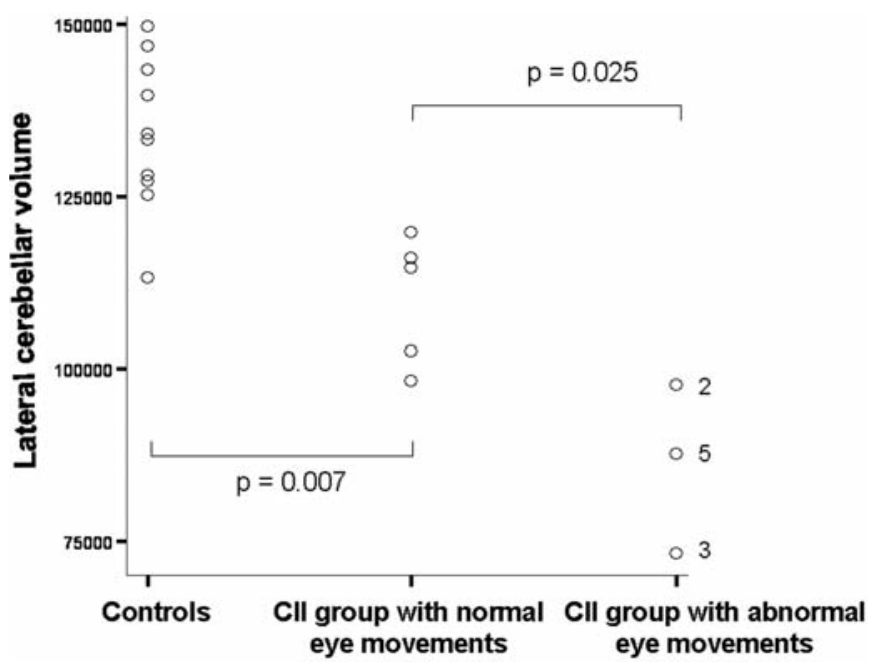

Figure 7: Lateral cerebellar volumes $\left(\mathrm{mm}^{3}\right)$ are shown in the controls, patients with CII who had normal eye movements, and patients with CII who had abnormal eye movements. The lateral cerebellar volumes are smallest in patients with CII who had abnormal eye movements (the numbers on the right correspond to the participants' number as presented in Table 3).

eye movements in comparison to CII patients with normal eye movements. In other words, a smaller posterior fossa size is associated with a relatively smaller vermis size in a subgroup of patients with CII, who have abnormal eye movements. Since our study is cross sectional, we do not know if this is a progressive process i.e., if the whole vermis was previously expanded in this subgroup of patients. However, the presence of a significantly expanded vermis lobules VI and VII area and an increase in the size of the longest longitudinal distance across the vermis on

\section{PF}

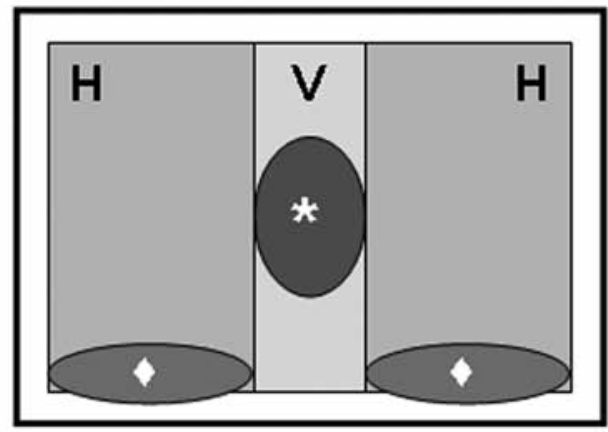

A

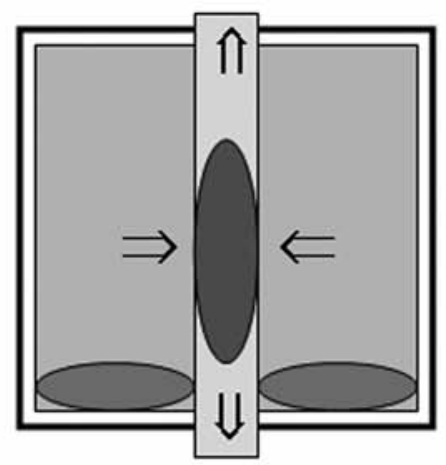

B

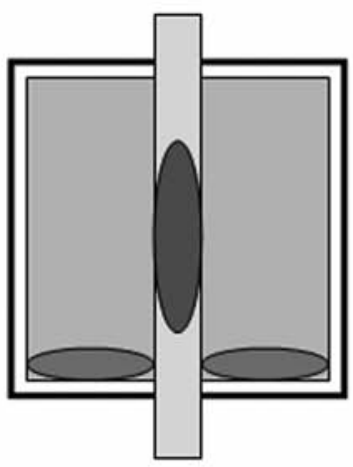

C

Figure 8: Models illustrating possible morphological changes in the posterior fossa and cerebellum in Chiari type II malformation. Coronal sections through the posterior fossa $(P F)$, cerebellar hemispheres $(H)$, vermis $(V)$, vermis lobules VI and VII $(*)$, and flocculus and paraflocculus $(\downarrow)$ are shown. The diagrams and areas are not drawn to scale. A) Normal. B) The sizes of the posterior fossa and cerebellar hemispheres are reduced in CII in comparison to that shown in (A) but the midsagittal vermis area, including vermis lobules VI and VII, is expanded (vertical arrows) secondary to compression (horizontal arrows) and vermis volume is preserved. Eye movements are normal. $C$ ) The posterior fossa and cerebellar hemispheres are reduced further in size in comparison to that in (B). There is a decrease in vermis size so that it is relatively smaller than the vermis size in (B). Midsagittal vermis lobules VI and VII area is only slightly expanded in comparison to that in (A) but significantly less expanded in comparison to that in (B). Eye movements are impaired. 
midsagittal MRI scans in the CII patients with abnormal eye movements in comparison to the controls, suggest that vermis compression and variable degrees of midsagittal vermis expansion is a feature of CII. This expansion is evidently not sufficient for the preservation of normal eye movements processing in many CII patients, as illustrated by nine of our patients.

Interestingly, we found that patients with CII who had abnormal eye movements not only had a non-expanded midsagittal vermis area but also had the smallest cerebellar volumes (Figure 5). This contrasts with our findings in patients with CII with normal eye movements, who had an expanded midsagittal vermis area including vermis lobules VI-VII area, larger medial cerebellar volumes, and larger cerebellar volumes than the CII patients with abnormal eye movements. However, total cerebellar volumes of CII patients with either normal or abnormal eye motion were still smaller than the controls (Figures 4 and 5).

In most ocular motor studies that have investigated the role of the cerebellum in eye movement control, the vermis, and the flocculi and paraflocculi were identified as playing key roles in processing eye movements. However, there is evidence that the cerebellar hemispheres are also involved in processing smooth pursuit and saccades. ${ }^{52-55}$ Therefore, it is possible that the severe reduction in the lateral cerebellar volumes, an approximate measure of cerebellar hemispheres size, seen in some of our patients with CII may be responsible, in part, for their eye movement abnormalities. However, the role of the cerebellar hemispheres in eye movement control is incompletely defined, ${ }^{26}$ with some studies suggesting that the cerebellar hemispheres are mainly involved in the behavioral aspects of eye movement control for example, changes in attention during self-paced saccades, ${ }^{54}$ and memory-guided saccades, but not visuallyguided saccades. ${ }^{52} \mathrm{~A}$ recent study in monkeys showed that the cerebellar hemisphere (lobule VII) is involved in the control of smooth pursuit speed and saccadic latency. ${ }^{55}$ Therefore, the reduction in cerebellar hemispheric size in CII may have contributed to the abnormal eye movements recorded in some of our patients.

The smooth pursuit system is affected most by the deformity of CII and was the only system affected in many of our patients with abnormal eye movements. All patients with subnormal smooth pursuit speed also had nystagmus. ${ }^{44}$ The findings likely reflect involvement of the flocculus and paraflocculus or their brainstem connections, ${ }^{44}$ and is consistent with the cerebellar hemispheres being more affected by the deformity of CII than the vermis. ${ }^{12,13,44}$ It is notable that saccadic abnormalities occurred only in association with smooth pursuit system abnormalities indicating dysfunction of the vermis, which is also involved in smooth pursuit processing. ${ }^{56}$ Lesions of vermis lobules VI and VII in monkeys cause a small decrease in steady smooth pursuit gain and a decrease in peak acceleration of initial smooth pursuit. ${ }^{56} \mathrm{In}$ a pursuit adaptation paradigm, where targets change velocity during on-going pursuit, normal animals can adaptively adjust their eye acceleration to match the new target velocity. Following lesions in the ocular motor vermis, this adaptive capability is impaired. The ocular motor vermis plays a role in smooth pursuit and its adaptive control. ${ }^{56}$

Patients with smooth pursuit and saccadic abnormalities had the smallest midsagittal vermis areas and posterior fossa areas on neuroimaging (Figure 3). There was one exception (participant Number 9, Tables 3 and 4, Figure 3), who likely had brainstem involvement because his VOR gain was subnormal. Brainstem function was mostly spared as suggested by the predominantly normal VOR gains, normal saccadic velocities, ${ }^{42}$ and typical absence of ocular motor nerve palsies in CII. ${ }^{23}$

We attribute the abnormal eye movements to the hindbrain deformity in CII, but we cannot fully exclude any contribution from other brain regions to the subnormal smooth pursuit gain and hypometric saccades. However, this appears unlikely based on the anatomical, neuroimaging, and neuropsychological changes described in this congenital malformation. ${ }^{10,14,29,50,57}$

The overall reduction in posterior fossa and cerebellar sizes does not uniformly affect the cerebellar structures or function in CII. In our formulation of the relation between ocular motor function and the structural abnormalities of CII (Figure 8), we have identified two types of structural changes in the cerebellum, each with a different functional outcome. The first, involving reduction in total and lateral cerebellar volumes, expansion of the midsagittal cerebellar vermis area including vermis lobules VI and VII, and relative preservation of the medial cerebellar volume, is associated with sparing of ocular motor functions (Table 5, Figure 8B). The second, involving severe reduction of the total cerebellar volume, relative reduction of the medial cerebellum volume, no expansion of the midsagittal vermis, and only slight expansion of midsagittal vermis lobules VI and VII, is associated with impairment of ocular motor functions (Table 5, Fig 8C).

Since our investigation was cross sectional, it is not clear if the contrasting configurations we have identified are progressive and mainly influenced by developmental changes occurring within the posterior fossa or static and largely determined early by the amount of CSF leakage in-utero and the subsequent size of the posterior fossa. Other factors may also be important including the presence of hydrocephalus or genetic factors.

Our investigations provide evidence that, despite the deformity of CII, ocular motor learning still occurs within the small and dysplastic cerebellum; because saccadic adaptation was evident even in the patients who had eye movement abnormalities (Table 3). ${ }^{43}$ Consistent with our normal adaptation of the saccadic system, other measures of adaptive skeletal motor learning have also been reported to be normal in patients with $\mathrm{CII},{ }^{58-60}$ including weight judgments, adaptation on reaching or ballistic movements, and mirror drawing performance.

The hindbrain dysplasia of CII does not of itself entail abnormal function. Our findings, which provide evidence for functional ocular motor circuits within deformed hindbrain structures in many patients with CII, also help to explain some of the clinical variability seen in patients with $\mathrm{CII}$ in relationship to anatomical changes that occur in this deformity. Vermis expansion with preservation of its volume and function in CII provide impetus for exploring brain function in other malformations.

\section{FUNDING}

This work was supported by 1) KidsAction; 2) Spina Bifida and Hydrocephalus Association of Canada; 3) Clinician Scientist training program award, Vision Science Research Program at the University of Toronto; and 4) Bloorview MacMillan Hospital foundation grants to M.S. Salman; 5) US National Institutes of 
Health Program Project [Grant P01 HD35946] "Spina bifida: Cognitive and neurobiological variability" to J. Fletcher and M. Dennis; and 6) Canadian Institutes of Health Research grants [MT5404, ME5909] to J.A. Sharpe.

\section{ACKNOWLEDGMENTS}

The authors thank Dr. Susan E. Blaser from the Division of Neuroradiology, The Hospital for Sick Children, Toronto, Ontario who analyzed the MRI scans qualitatively, and Dr. Michael E. Brandt, Department of Radiology, University of Texas Health Science Center, Houston, Texas who analyzed the MRI volumetrics. We also thank Dr. M. Eizenman, Mrs. I. Dror, and Mr. A. Blakeman for their support and we thank the participants and their families for their time and enthusiasm.

\section{REFERENCES}

1. Fletcher JM, McCauley SR, Brandt ME, Bohan TP, Kramer LA, Francis DJ, et al. Regional brain tissue composition in children with hydrocephalus: relationships with cognitive development. Arch Neurol. 1996;53:549-57.

2. McLone DG, Knepper PA. The cause of Chiari II malformation: Aaunified theory. Pediatr Neurosci. 1989;15:1-12.

3. Sarnat HB. Molecular genetic classification of central nervous system malformations. J Child Neurol. 2000;15(10):675-87.

4. Gilbert JN, Jones KL, Rorke LB, Chernoff GF, James HE. Central nervous system anomalies associated with meningomyelocele, hydrocephalus, and the Arnold-Chiari malformation: reappraisal of theories regarding the pathogenesis of posterior neural tube closure defects. Neurosurgery. 1986;18:559-64.

5. Sutton LN, Adzick NS, Bilaniuk LT, Johnson MP, Crombleholme TM, Flake AW. Improvement in hindbrain herniation demonstrated by serial fetal magnetic resonance imaging following fetal surgery for myelomeningocele. JAMA. 1999; 282:1826-31.

6. Wagner W, Schwarz M, Perneczky A. Primary myelomeningocele closure and consequences. Curr Opin Urol. 2002;12:465-8.

7. Barkovich AJ. Congenital malformations of the brain and skull / Congenital anomalies of the spine. In: Barkovich AJ, editor. Pediatric neuroimaging. Philadelphia, PA: Lippincott Williams \& Wilkins; 2000. p. 330-7.

8. Hori A. Chiari anomaly type II without cerebellar herniation. Acta Neuropathol. 2002;105:193-4.

9. Brocklehurst G. A quantitative study of a spina bifida foetus. J Pathol. 1969;99:205-11

10. Pilu G, Romero R, Reece EA, Goldstein I, Hobbins JC, Bovicelli L. Subnormal cerebellum in fetuses with spina bifida. Am J Obstet Gynecol. 1988;158:1052-6.

11. Sener RN. Cerebellar agenesis versus vanishing cerebellum in Chiari II malformation. Comput Med Imaging Graph. 1995;19: 491-4.

12. Boltshauser E, Schneider J, Kollias S, Waibel P, Weissert M. Vanishing cerebellum in myelomeningocele. Eur $\mathrm{J}$ Paediatr Neurol. 2002;6:109-13.

13. Emery JL, Gadsdon DR. A quantitative study of the cell population of the cerebellum in children with myelomeningocele. Dev Med Child Neurol. 1975;15 Suppl 29:20-5.

14. Variend S, Emery JL. The weight of the cerebellum in children with myelomeningocele. Dev Med Child Neurol. 1973:15(Suppl 29): 77-83.

15. Harding BN, Copp AJ. Malformations. In: Graham DI, Lantos PL, editors. Greenfield's neuropathology. London: Edward Arnold; 2002. p. 376-86

16. Dennis M, Edelstein K, Hetherington R, Copeland K, Frederick J, Blaser SE, et al. Neurobiology of perceptual and motor timing in children with spina bifida in relation to cerebellar volume. Brain. 2004; $127: 1-10$

17. Salman MS. The cerebellum: it's about time! But timing is not everything: new insights into the role of the cerebellum in timing motor and cognitive tasks. J Child Neurol. 2002;17:1-9.
18. Ivry RB, Keele SW, Diener HC. Dissociation of the lateral and medial cerebellum in movement timing and movement execution. Exp Brain Res. 1988;73:167-80.

19. Mauk MD, Medina JF, Nores WL, Ohyama T. Cerebellar function: coordination, learning or timing? Curr Biol. 2000;10:R522-5.

20. Bloedel JR, Bracha V, Larson PS. Real time operations of the cerebellar cortex. Can J Neurol Sci. 1993;20 Suppl 3:S7-18.

21. Huber-Okrainec J, Dennis M, Brettschneider J, Spiegler BJ. Neuromotor speech deficits in children and adults with spina bifida and hydrocephalus. Brain Lang. 2002;80:592-602.

22. Wallace SJ. The effect of upper-limb function on mobility of children with myelomeningocele. Dev Med Child Neurol. 1973;15 Suppl 29:84-91.

23. Lennerstrand G, Gallo JE. Neuro-ophthalmological evaluation of patients with myelomeningocele and Chiari malformations. Dev Med Child Neurol. 1990;32:415-22.

24. Lennerstrand G, Gallo JE, Samuelsson L. Neuro-ophthalmological findings in relation to CNS lesions in patients with myelomeningocele. Dev Med Child Neurol. 1990;32:423-31.

25. Biglan AW. Ophthalmological complications of meningomyelocele: A longitudinal study. Trans Am Ophthalmol Soc. 1990;88:389-462.

26. Leigh RJ, Zee DS. The neurology of eye movements, 4th ed. New York: Oxford University Press; 2006. p. 20-53.

27. Wills KE. Neuropsychological functioning in children with spina bifida and/ or hydrocephalus. J Clin Child Psychol. 1993;22: 247-65.

28. Dennis M, Fitz CR, Netley CT, Sugar J, Harwood-Nash DC, Hendrick EB, et al. The intelligence of hydrocephalic children. Arch Neurol. 1981;38:607-15.

29. Salman MS. The cerebellum in Chiari type II malformation. Neuroembryol Aging. 2008;5:14-22.

30. Daroff RB. A personal introduction to eye movements. Ann NY Acad Sci. 2002;956:1-6.

31. Takagi M, Zee DS, Tamargo RJ. Effects of lesions of the oculomotor vermis on eye movements in primate: saccades. J Neurophysiol. 1998;80:1911-31.

32. Fukushima K, Buharin EV, Fukushima J. Responses of floccular Purkinje cells to sinusoidal vertical rotation and effects of muscimol infusion into the flocculus in alert cats. Neurosci Res. 1993; 17:297-305

33. Yakusheva T, Shaikh A, Green A, Blazquez P, Dickman J, Angelaki D. Purkinje cells in posterior cerebellar vermis encode motion in an inertial reference frame. Neuron. 2007;54:973-85.

34. Mossman SS, Bronstein AM, Gresty MA, Kendall B, Rudge P. Convergence nystagmus associated with Arnold-Chiari malformation. Arch Neurol. 1990;47:357-9.

35. Collard M, Strubel-Streicher D, Eber AM, Remy C. Les troubles oculomoteurs dans les malformations d'Arnold-Chiari. Rev Neurol. 1980;136:531-8.

36. Nishizaki T, Tamaki N, Nishida Y, Matsumoto S. Bilateral internuclear ophthalmoplegia due to hydrocephalus: a case report. Neurosurgery. 1985; 17:822-5.

37. Arnold AC, Baloh RW, Yee RD, Hepler RS. Internuclear ophthalmoplegia in the Chiari type II malformation. Neurology. 1990;40:1850-4

38. Spooner JW, Baloh RW. Arnold-Chiari malformation: improvement in eye movements after surgical treatment. Brain. 1981;104: 51-60.

39. Longridge NS, Mallinson AI. Arnold-Chiari malformation and the otolaryngologist: Place of magnetic resonance imaging and electronystagmography. Laryngoscope. 1985;95:335-9.

40. Pieh C, Gottlob I. Arnold-Chiari malformation and nystagmus of skew. J Neurol Neurosurg Psychiatry. 2000;69:124-6.

41. Lewis AR, Kline LB, Sharpe JA. Acquired esotropia in Arnold Chiari I malformation. J Neuroophthalmol. 1996;16:49-54.

42. Salman MS, Sharpe JA, Eizenman M, Lillakas L, To T, Westall C, et al. Saccades in children with spina bifida and Chiari type II malformation. Neurology. 2005;64:2098-101.

43. Salman MS, Sharpe JA, Eizenman M, Lillakas L, To T, Westall C, et al. Saccadic adaptation in Chiari type II malformation. Can J Neurol Sci. 2006;33:372-8. 
44. Salman MS, Sharpe JA, Lillakas L, Steinbach MJ, Dennis M. Smooth ocular pursuit in Chiari type II malformation. Dev Med Child Neurol. 2007;49:289-93.

45. Salman MS, Sharpe JA, Lillakas L, Dennis M, Steinbach MJ. The vestibulo-ocular reflex during active head motion in Chiari II malformation. Can J Neurol Sci. 2008;35(4):495-500.

46. Salman MS, Sharpe JA, Lillakas L, Dennis M, Steinbach MJ. Visual fixation in Chiari type II malformation. J Child Neurol. 2009;24:161-5.

47. Barash S, Melikyan A, Sivakov A, Zhang M, Glickstein M, Thier P. Saccadic dysmetria and adaptation after lesions of the cerebellar cortex. J Neurosci. 1999;19:10931-9.

48. Dennis M, Fletcher JM, Rogers T, Hetherington R, Francis DJ. Object-based and action-based visual perception in children with spina bifida and hydrocephalus. J Int Neuropsychol Soc. 2002;8: 95-106.

49. Altman DG. Practical statistics for medical research. New York: Chapman and Hall London; 1995.

50. Salman MS, Blaser S, Sharpe JA, Dennis M. Cerebellar vermis morphology in children with spina bifida and Chiari type II malformation. Childs Nerv Syst. 2006;22(4):385-93.

51. Tsai T, Bookstein FL, Levey E, Kinsman SL. Chiari-II malformation: a biometric analysis. Eur J Pediatr Surg. 2002;12 Suppl 1:S12-8

52. Nitschke MF, Binkofski F, Buccino G, Posse S, Erdmann C, Kömpf $\mathrm{D}$, et al. Activation of cerebellar hemispheres in spatial memorization of saccadic eye movements: an fMRI study. Hum Brain Mapp. 2004;22(2):155-64.
53. Straube A, Scheuerer W, Eggert T. Unilateral cerebellar lesions affect initiation of ipsilateral smooth pursuit eye movements in humans. Ann Neurol. 1997;42(6):891-8.

54. Dieterich M, Bucher SF, Seelos KC, Brandt T. Cerebellar activation during optokinetic stimulation and saccades. Neurology. 2000;54(1):148-55.

55. Ohki M, Kitazawa H, Hiramatsu T, Kaga K, Kitamura T, Yamada J, et al. J Neurophysiol. 2009;101(2):934-47.

56. Takagi M, Zee DS, Tamargo RJ. Effects of lesions of the oculomotor cerebellar vermis on eye movements in primate: smooth pursuit. J Neurophysiol. 2000;83:2047-62.

57. Fletcher JM, Dennis M, Northrup H, Barnes MA. Hannay HJ, Landry S, et al. Spina bifida: genes, brain, and development. Int Rev Res Ment Retard. 2004;29:63-117.

58. Colvin AN, Yeates KO, Enrile BG, Coury DL. Motor adaptation in children with myelomeningocele: comparison to children with ADHD and healthy siblings. J Int Neuropsychol Soc. 2003;9: 642-52.

59. Edelstein K, Dennis M, Copeland K, Frederick J, Francis DJ, Hetherington CR, et al. Motor learning in children with spina bifida: dissociation between performance level and acquisition rate. J Int Neuropsychol Soc. 2004;10:1-11

60. Dennis M, Jewell D, Edelstein K, Brandt ME, Hetherington R, Blaser SE, et al. Motor learning in children with spina bifida: intact learning and performance on a ballistic task. J Int Neuropsychol Soc. 2006;12(5):598-608. 